\title{
A PROPOSED FRAMEWORK FOR MEASURING THE EFFECTIVENESS OF SOCIAL MEDIA: A STUDY OF IRISH TOURISM
}

\author{
COLM BARCOE \& GARVAN WHELAN \\ Institute of Technology Tallaght, Ireland
}

\begin{abstract}
Over the past five years, visitations of American holidaymakers to Ireland have grown exponentially owing to the online strategies of Tourism Ireland, a Destination Marketer (DMO) with a meagre budget which is extended by their understanding of best practices to maximise their monetary allowance. This suggested framework incorporates a range of Key Performance Indicators (KPIs) such as financial, marketing and operational that offer a scale of measurement from which the Irish DMO can monitor the success of each promotional campaign when targeting the US and Canada. These are presented not as final solutions but rather as suggestions based on empirical evidence obtained from both primary and secondary sources. This research combines the wisdom extracted through qualitative methodologies with the objective of understanding the processes that drive both emergent and agile strategies. The study extends the work relative to performance and examines the role of social media in the context of promoting Ireland to North America. There are two main themes that are identified and analysed in this investigation, these are the approach of the DMO when advocating Ireland as a brand and the benefits of digital platforms set against a proposed scale of KPIs, such as destination marketing, brand positioning and identity development. The key narrative of this analysis is to focus on the power of social media when capitalising upon marketing opportunities, operating on a relatively small budget. This will always be a relevant theme of discussion due to the responsibility of an organisation like Tourism Ireland operating under the restraints imposed by government funding. The overall conclusions of this research may help inform those concerned with the implementing of social media strategies develop clearer models of measurement when promoting a destination to North America. The suggestions of this study will benefit small and medium enterprises particularly.
\end{abstract}

Keywords: Ireland, North America, destination, marketing, DMO, performance, framework, measurement, qualitative, methodology.

\section{INTRODUCTION}

Social media have a vital contribution to make as part of a digital marketing strategy; the channels create both awareness and engagement when integrated with a destination marketing campaign. Tourism Ireland creates and procures content for the purposes of promoting Ireland as a brand internationally TI [2]. The DMO operates on a meagre budget, in the absence of social media; this promotional content would not have the reach that it has presently. In this situation the DMO boasts a substantial return on investment (ROI) in relation to the North American market due to alliances with those who film TV and Movies in Ireland [2]. This paper illustrates how the metrics applied by the DMO benefits Irish tourism and can assist the SMEs that contribute to the service promoted by Tourism Ireland (Barcoe and Barcoe [3]). The study will offer insights into the DMO's approach to maximising their budget and achieving objectives that extend beyond their financial means using social media and electronic word of mouth (eWOM) (Hoffman and Fodor [4]). The data that was obtained through in-depth interviews with those responsible for both designing and implementing digital strategies when promoting Ireland as a brand and a Netnographic audit of the DMOs online activities, will be analysed to offer a suggestive framework that may deliver solutions as to how ROI can be achieved in relationship marketing (CRM) 
through the use of social media channels. This research will use the model suggested from Pike and Page [1] in relation to destination marketing to gauge the effectiveness of social media channels in terms of brand performance. The aim of this study is to identify a framework that may highlight the presence of ROI in relation to social media investment through two methods of qualitative analysis (Barcoe and Whelan [5]). Nvivo 11+ is a software package used by the researcher to capture activities that not only lead to online consumer engagement, but also the direct route to the maximisation of investment through the creation of ancillary promotions using social media channels (TI [2]).

In the context of tourism, consumer engagement has been shown to increase awareness and loyalty of a brand (So et al. [6]). Social media channels, when used effectively have increased the levels of engagement using traditional Relationship marketing (CRM) methods in a digital marketing strategy (Harrigan et al. [7]). However, to date, every framework offered by academics in the field of destination marketing have been suggestive because of the nature of social media in relation to deviant consumer's demeanours (Sigala [8]). This research is analysis of the Irish DMO and their activities when promoting Ireland to North America using social media and the Key Performance Indicators (KPIs) and traditional matrices they use to achieve their objectives in relation to North American visitations to Ireland. The DMO uses CRM metrics such as awareness and engagement using social analytics to measure their ROI in relation to strategies implemented. This study will analyse the suggested frameworks of others through literature review and correlate the activities of the Irish DMO in relation to these suggestions.

The aim of this research is to analyse the effectiveness of social media channels in relation to DMOs with smaller budgets and identify where ROI as a metric can be achieved. The empirical data of this paper reveals the effect that partnerships and alliances can have on a small destination when procuring content for social media channels in a cost-effective manner. While other authors like Chaffey [9], Kaske et al. [10] suggest how social media activities can generate ROI, there are no hard and fast rules. However, the basic principles of CRM assist in achieving KPIs using social media channels. The paper outlines the adaptability of social media that allows the Irish DMO a more agile strategy to benefit their budget. The data obtained for this study highlights the use of traditional matrices and marketing fundamentals. The research also reveals the wisdom and knowledge of Tourism Ireland when applying traditional metrics to create ancillary promotions. This study adds to tourism research as it analyses marketing strategies in relation to Ireland and North America where engagement is an antecedent to the content creation.

\section{LITERATURE}

Barcoe and Barcoe [3] and Wright [11] highlight the cultural link that constitutes an antecedent to the engagement of the North American Holidaymaker in relation to Ireland as a brand. Tourism Ireland reveals how they exploit this type of engagement using CRM strategies through social media channels (TI [2]). Pike and Page [1] describe this activity as brand positioning as part of their destination marketing framework.

Felix et al. [12] believe that brand performance can deliver ROI due to the benefits of social media activity. Kaske et al. [10] posit that the role of consumer knowledge affords the DMO the opportunity to measure the KPIs that best serve the CRM strategy when using social media as a marketing channel. Hoffman and Fodor [4] believe that a framework measuring the financial benefits of digital marketing must be activity based and based on KPIs. So et al. [6] accede with this assessment as they suggest a 25 item behavioural scale that measures consumer behaviours through social media activity in relation to brand 
engagement. Harrigan et al. [7] reduces the So et al. [6] to 11 items that are applicable to organisations of all sizes.

Kumar and Mirchandani [13] suggest that ROI in relation to social media is relative to its benefits for SMEs that increase their brand loyalty. Merilinaen [14] suggests that the most cost-effective approach for a smaller enterprise in the context of tourism is the adaption of the DMO message through online partnerships. Kumar and Mirchandani [13] use a case study of an SME to highlight the relative benefits of social media in relation to investment return. Blanchard [15] outlines a four-step plan from which a company can achieve financial return using social media channels.

Table 1 illustrates Blanchard's [15] four steps to the monitoring of investment return using social media channels. This approach follows a succession of academics within the literature that suggest aligning social media activity with metrics like Owyang [16] who devises a pyramid to measure the effectiveness of social media in the context of modern marketing. This metric is a derivative of a search optimisation pyramid suggested by Chaffey [17] when highlighting the qualities of using digital marketing campaigns.

Fig. 1 emphasises the suggested metrics of Owyang's [16] ROI pyramid that segregates social media activities into three main areas, first is operational savings that were particularly import post the recession of 2008. Secondly the author looks at the increase productivity from a marketing perspective and finally the strategic advantages in terms of differentiation that social media channels offer companies of all capacities. Pradiptarini [18] accedes with this theory when analysing the cost effectiveness of using social media channels to identify and target a chosen demographic. This in tourism pertains to the activities of the DMO and how each social platform contributes to the overall message broadcasted by the organisation (Hoffman and Fodor [4], Fisher [20]). Pike and Page [1] attribute this to both brand identity and brand performance in relation to destination marketing.

Table 1: Blanchard's (2011) Four step social media program.

(1) Creating the social company

(2) Aligning social media with business goals

(3) Planning for performance measurement

(4) Establishing clarity of vision, purpose and execution

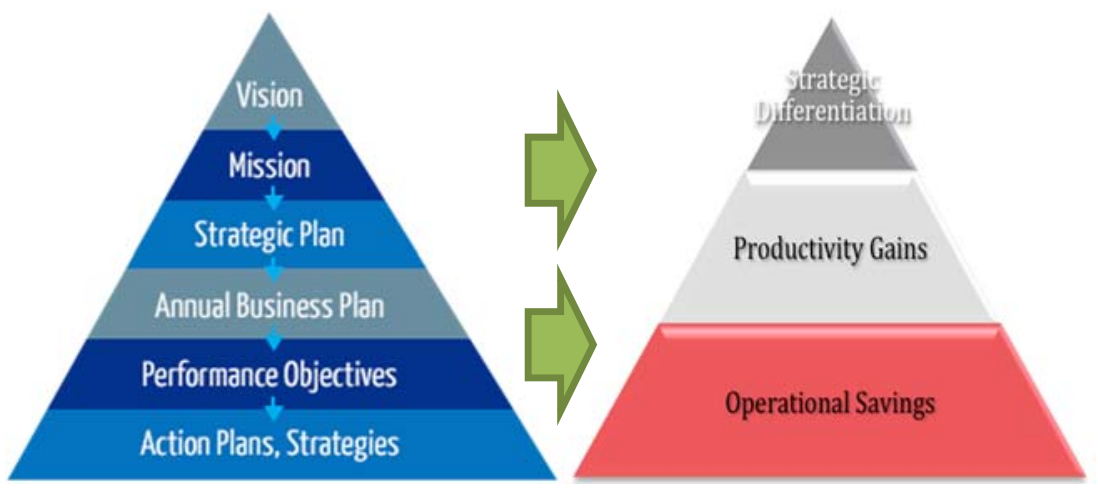

Figure 1: The progression of the traditional marketing pyramid to Owyang's [16] pyramid with the mission pyramid suggested by Chaffey [17] as a comparison. 


\section{METHODOLOGY}

The research for this study began with the investigation of the activities of the Irish DMO when using social media as a digital marketing channel in attracting the North American holidaymaker to Ireland. During the course of the study Pike and Page's [1] model was used as a framework to categorise the empirical findings. The empirical study itself was conducted during the summer of 2017 and comprised of three primary sources of information. Firstly, the in-depth semi-structured interviews with those who are responsible for both designing and implementing digital marketing strategies for tourism purposes. Secondly, NVivo 11+, a software package that codes and captures social media activities and acts as an assistant to the researcher, was used to monitor destination marketing campaigns and code the in-depth interviews and any relevant occurrences for the study's purpose. Finally, 250 North Americans were surveyed in relation to Ireland as a destination and their use of social media.

The 20 industry-based contributors to this research included general managers, Tour operators, SMEs, Airlines, Academics previously published in the area of CRM and DMOs, all of who were responsible for implementing the most cost effective strategy possible for their organisation. The majority of the interviewees viewed social media as a required channel as part of both a digital and tourism strategy. It was the larger companies that were the most adept at implementing their own frameworks to assist them measure the benefits of social media in relation to CRM and brand engagement. This field of study is interesting as it pertains to two civilisations that are culturally linked and awareness of Ireland among North Americans is pre-existent. This is why Ireland as a brand is unique in terms of CRM strategies when approaching North America.

Having established the first theme of cultural links, the other themes that emanated from the coding process were all themes that pertained to the most cost effective approach to marketing Ireland to North America and this was conclusive as $99 \%$ of the interviewees confirmed this to be social media channels and $67 \%$ of those interviewed believed social media to be antecedent to destination purchase in relation to tourism.

Once the coding was completed for this study, it was decided to use Pike and Page [1] as a framework to categorise the benefits of social media use. Because this is a destination marketing model that separates destination marketing into traditional categories it became simpler to view the cost effectiveness of social media KPIs using this model as a suggestive framework for this study. The framework suggested by Pike and Page [1] measures both the internal and external activities of the DMO and how this affects sustained destination competitiveness, destination brand identity development, destination brand positioning, destination marketing performance and measurement and tracking. Each of these categories have been central to studies like Kumar and Mirchandani [13] and Harrigan et al. [7]. The implementation of the suggestive framework began during the post-coding of this study's interviews. The themes of the study quickly emerged and each theme fit the categories suggested by Pike and Page [1].

Fig. 2 is the framework suggested by Pike and Page [1], the structure is quite comprehensive and monitors both the internal and external performances of destination marketing. However, when aligning the framework with the empirical evidence social media and its cost- effectiveness creates a different dynamic that is present due to the cultural link between Ireland and North America.

\section{FINDINGS}

When analysing the Irish DMO's activities under the categories of Pike and Page [1] there were some initial findings that were unique to Ireland as a brand in relation to North America. Firstly, in relation to brand competitiveness the comparative advantage is the resource of the 


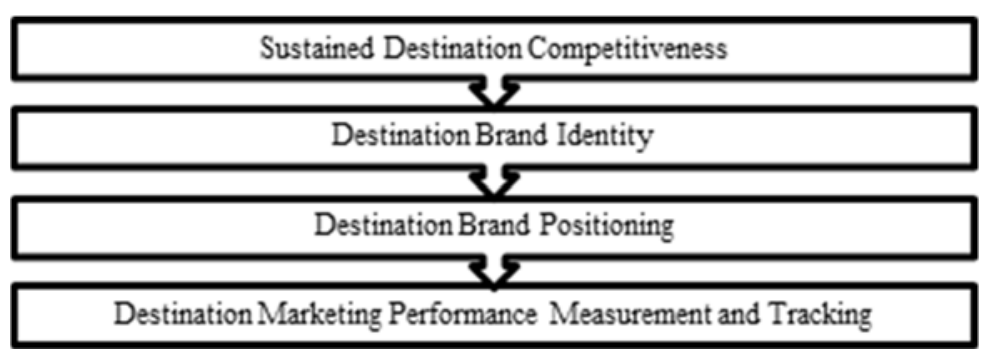

Figure 2: Pike and Page's [1] Destination Marketing Framework.

cultural link with over $44 \%$ of North Americans surveyed for this study visiting Ireland to discover their heritage and another $44 \%$ culturally curious about the destination. The most important percentage for this study was the $12 \%$ that stated they were inspired to travel to Ireland due to the influence of social media messaging, of this $12 \%, 87 \%$ were millennials which creates an opportunity for the DMO to audit social media as a resource using Pike and Page [1]. This finding highlights the contribution of social media in relation to CRM and the younger demographic in the future.

The case in point is the Game of Thrones campaign where the DMO implemented an ancillary strategy across social media that resulted in both brand development and furthered North American engagement with Ireland as a brand. The project titled the Game of Doors cost $€ 20,000$ to implement and yielded in the region of $€ 57,000$ in the first six months of its existence. While highlighting an $81.5 \%$ profit margin, this is only one aspect of social media usage. The empirical evidence in this case also relates to the suggestive framework as it constitutes a comparative advantage. This type of promotion creates a destination experience that correlates with effective destination management as suggested by Pike and Page [1].

\subsection{Destination identity development}

During the course of the interviews the interviewees described how they created and measured their brand identity. When first approaching the use of social media, the Irish DMO spent $€ 1.6$ million on the development of a coastline called the Wild Atlantic Way (WAW) as part of a campaign called "the gathering" this reimagined Ireland's identity internationally using TV and social media channels to promote a more contemporary Ireland. The effect on the North American audience delivered an initial 1 million Facebook followers which has now grown to over 4 million. The WAW constantly trends on Twitter and creates a forum for the North Americans to engage with the brand as the DMO launches its newest campaigns. In relation to CRM cost effectiveness social media creates the following.

Fig. 3 highlights the KPIs used when measuring social media effectiveness in relation to identity development. The first category is strength where the differentiation between Ireland as a brand in North America can measure by the engagement of the audience with the message broadcasted by the DMO. This can be measured by Facebook interactions, Twitter awareness and YouTube searches. YouTube then dictates the relevance of the searches as North Americans look for the Irish vacation particular to their needs such as surfing holidays in Waterford. This is where social media becomes most cost effective as the channel will highlight advertisements that relate to a type specific vacation in Ireland which creates brand identity. In relation to the second set of KPIs in relation to identity development the stature of the brand is measured. This is done by looking at how the brand is viewed by the North 


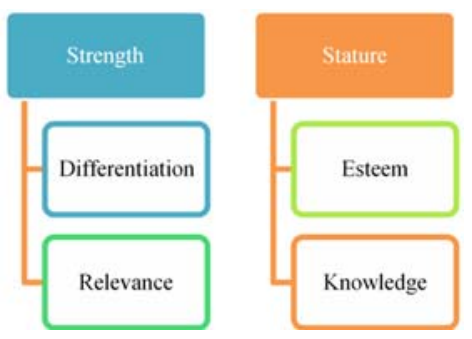

Figure 3: Brand identity development KPIs when using social media channels.

American. In this case the brand is emotional in context as the two civilisations are culturally linked. This allows the DMO to use Facebook as a platform to engage with the North American and organically influence an online conversation that motivates the audience to want to purchase the holiday through social media interaction. The messages broadcast across the various channels afford the North American knowledge of Ireland as a brand that will not only further engagement but also inspire purchases. While these activities are constant social media reduces advertising costs due to the level of engagement and influence created. The most important feature of social media usage in relation to brand identity is eWOM across social media channels when North Americans add to the identity of Ireland as a brand, this ripple effect is the cost-effective nature of CRM using social media.

\subsection{Destination brand positioning}

When marketing Ireland to North America it is important to the DMO that the brand has reach through social media messaging. This begins with the suite of platforms that generate the engagement levels. The organic influencers across social media will ultimately create the ROI in this case as they will further position the brand across all channels. The DMO in this case must listen to the social audience and turn the information obtained into a new emergent strategy that maximises the initial investment. This may include strategic partnerships with Lonely Planet and Lucas films. All of these activities drive traffic towards Ireland.com and the websites of other Irish stakeholders. In this case this allows the DMO to use ancillary promotions to maximise their budget. This offsets the cost of advertising and maximises brand positioning. Tourism Ireland spent $€ 22 \mathrm{~m}$ on promoting Ireland in North America in 2017 but by using social media received $€ 586 \mathrm{~m}$ in ancillary advertising. This is a $486 \%$ ROI using social media channels as part of a brand positioning strategy. This is as Chaffey [9] describes as social insights where the organic positioning of a brand occurs through social media channels as an ancillary agent. Mae-Kim [19] believes that this is where the true benefit of social media can be felt.

Fig. 4 highlights the approach to social media promotion that is used when marketing Ireland as a brand to North America. This particular model influences brand positioning as it pertains to the consideration of extending the brands reach to advocate conversion using ancillary activities. This is best illustrated by Tourism Ireland's Star Wars campaign launched 23 December 2017. The promotion of the movie is used by the organisation to drive traffic to the organisation's social media platforms where the fans of the movie can engage with the movie's iconic location. This positions Ireland as a brand for 2018 when marketing to North America and highlights the maximisation of budget through alliances with Lucas 


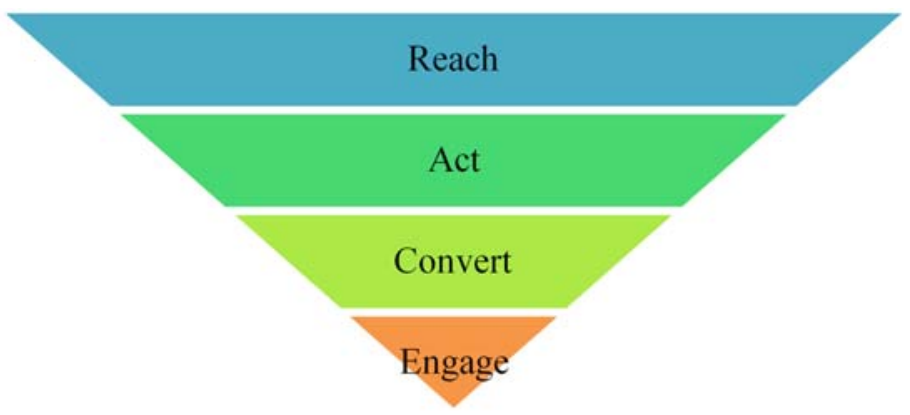

Figure 4: Chaffey's [9] process of social media promotion.

films and social media as a brand positioner. In terms of ROI this pertains to customer lifetime value where the North American further associates the brand with pop culture. The interviewees of this study believe that this creates a desire among North Americans to want to travel to Ireland. When the brand achieves its position this way across social media channels, shares, likes and comments create a customer lifetime value (CLV), this in terms of social media is harder to calculate. The empirical wisdom of this study reveals this to be $5 \%$ per customer per day basing the calculation on a 28 day social media cycle. However, this is only suggestive and metrics like awareness, engagement, unique visits and return visits are far more valuable when measuring brand health and positioning.

\subsection{Destination marketing performance measurement and tracking}

When analysing the performance of a brand the interviewees had a variation of methods. The Irish DMO use KPI scales while the Irish SMEs use TripAdvisor reviews and scores in the post consumption stage. Another approach is the use of a BCG matrix that monitors both the purchases of the North American holidaymaker and the social media activity around such purchases. Conversocial and Synthesio are used as analytical measurements to analyse the level of North American engagement, while platform analytics through Facebook and Twitter track the real time ROI once a strategy has been implemented.

In terms of the SMEs TripAdvisor is the analytic of choice. The platform provides insights as to the quality of experience had by the North American holidaymaker (NAH). The Irish stakeholders of this study conceded that TripAdvisor alone generates enough information to perform a balance scorecard.

Fig. 5 is a balanced scorecard used by $48 \%$ of those interviewed for this study; this framework was used mainly in conjunction with the TripAdvisor platform to provide further insights into the North American holidaymaker in the post consumption phase. While this measurement is traditional, the interviewees of this study believed that it not only categorises the effect of social media on their service but it also provides key indicators of how their performance as a service provider can be improved in relation to the North American holidaymaker in the future. The interviewees believed that this platform is essential from the customer perspective as the organisation can view their company from the customer perspective within the platform settings. Xiang and Gretzel [21] highlight this platform in relation to the review facility. The interviewees of this study believe that this platform offers another aspect of analysis and that is the ranking system, $96 \%$ of the $48 \%$ that use the platform relate this directly to ROI and ticket sales. 


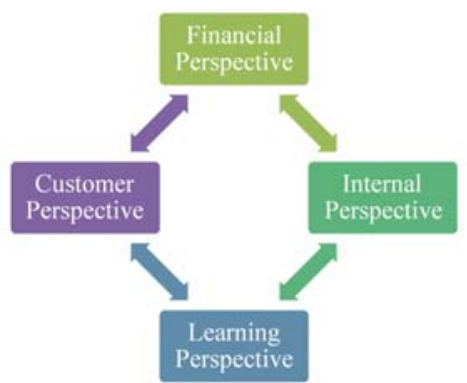

Figure 5: Measuring social media ROI using a balanced scorecard.

In relation to the $\mathrm{BCG}$ matric and performance tracking and measurement, this is used by the airlines that were interviewed for this study. Shaw [22] confirms the use of Ansoff and BCG matrices to be industry standard. This measurement is more pre and post consumption analysis in relation to CRM. The airlines monitor the physical traffic to Ireland from North America and the virtual engagement with the company through social media channels. This then gets correlated with ROI to predict what the next viable North American route to Ireland might be. The reality of this approach is the flexibility of the airline business in terms of flight origin.

Fig. 6 highlights the flexibility of the Irish airline companies when monitoring ROI through social media activity. The interviewees of this study believed that social media engagement directly indicated where destination purchase may emanate from using this measurement. In this example the routes with the least amount of social media engagement generated little ancillary sales. This model reveals KPIs such as ROI, brand awareness, consumer engagement and future purchases.

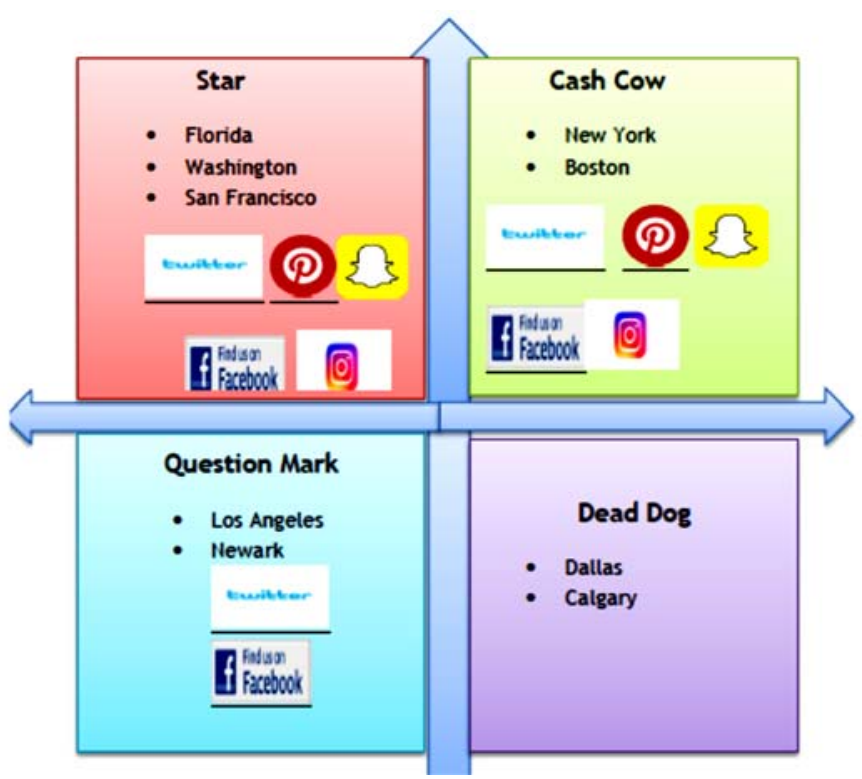

Figure 6: BCG Matrix using social media activity as a performance analysis. 
The Irish DMO when interviewed conceded that KPI scales are often the best approach to measuring their performance. This is interesting as they use their social media channels of choice to promote rather than prospect the destination. The ROI in this sense is based on other metrics. The approach of Harrigan et al. [7] and So et al. [6] are the most relatable models of measurement in this case. The DMO is looking to create a new strategy in an existing market and as Shaw [22] reveals an Ansoff matrix is often the framework of choice for a DMO. Fauver [23] posits that a DMO must remain relevant when using social media as a digital marketing channel. This is evident in the approach of Tourism Ireland as they use North American pop culture such as Star Wars to remain relevant and generate North American engagement using social media as the intermediary for implementing such strategy. This extends their budget and is a derivative of social analytics measured by KPI scales.

Table 2 is an example of how the Irish DMO analyses ROI relative to CRM activities using social media. Both sections of the table analyse the productivity of reach and impressions much like an SEO dashboard this scale measures the ROI of both paid and nonpaid promotion across social media channels. The metrics range from clicks and views to shares and comments all of which directly correlate with consumer engagement. The activities are all relatable to eWOM and ancillary purchases by the North American holidaymaker. This scale differs slightly from a more commercially driven scale as it is concerned only with destination purchase through North American engagement leading to ROI. The financial return in this case is purely strength of performance and measuring the DMOs effectiveness in relation to CRM.

Table 2: Social metrics KPI scale.

\begin{tabular}{|l|l|}
\hline \multicolumn{1}{|c|}{ Platform } & \multicolumn{1}{c|}{ KPIs } \\
\hline Social \\
\hline Facebook & $\begin{array}{l}\text { Links, impressions, social shares, video } \\
\text { views }\end{array}$ \\
\hline Twitter & $\begin{array}{l}\text { Reach, impressions, links, shares, } \\
\text { unique visitors }\end{array}$ \\
\hline Instagram & Reach, impressions, social shares \\
\hline YouTube & Video views, comments, organic clicks \\
\hline Google + & Organic clicks \\
\hline
\end{tabular}

\begin{tabular}{|l|l|}
\hline \multicolumn{2}{|c|}{ KPI scale of online advertisements via paid media } \\
\hline \multicolumn{2}{|c|}{ Platforms } \\
\hline \multicolumn{2}{|c|}{ KPIs } \\
\hline Google & $\begin{array}{l}\text { Reach, Impressions, Downloads, impressions, } \\
\text { unique visitors, Page views, links clicks }\end{array}$ \\
\hline Facebook & $\begin{array}{l}\text { Reach, Impressions, Downloads, impressions, } \\
\text { unique visitors, Page views, links clicks }\end{array}$ \\
\hline Remarketing & Reach and Impressions \\
\hline Content distributors & $\begin{array}{l}\text { Reach, impressions, unique visitors, } \\
\text { downloads, link clicks }\end{array}$ \\
\hline
\end{tabular}


Table 3: Correlating this study with the Pike and Page (2014) framework.

\begin{tabular}{|l|l|}
\hline The Present Exploration & Aspects of Pike and Page (2014) Framework \\
\hline North American desire to travel to Ireland & Destination Brand Development \\
\hline $\begin{array}{l}\text { Capitalisation of market opportunity } \\
\text { Theme 4: Role of Social Media in the future }\end{array}$ & Destination Brand Positioning \\
\hline Social Media Promotion Correlation with ROI & $\begin{array}{l}\text { Destination Marketing Performance } \\
\text { Measurement and Tracking }\end{array}$ \\
\hline
\end{tabular}

\section{CONCLUSIONS AND IMPLICATIONS}

This paper adds to the already growing literature on social media. The study reveals the activities particular to Ireland and North America that highlights the use of social media as not only as a digital marketing channel for consumer engagement but also a CRM technique that generates ROI through various ancillary activities. This study uses the Pike and Page [1] as a framework to categorise the type of CRM activities within a destination marketing strategy that can generate a return on investment while maximising a budget through the use of social media as engagement channels. The unique aspect of marketing Ireland to North America is the cultural link that creates awareness as the antecedent to social media promotion.

Table 3 identifies the correlates the empirical information obtained for this study with the Pike and Page [1] suggestive framework for destination marketing. The implications of this highlight the recommendations of Evans [24] and the theory proposed by Zuninga and Jung [25]. Hoffman and Fodor [4] posit that any measurement of social media effectiveness can only be suggestive. In this study the empirical research delivers the same result, however, the use of traditional marketing matrices and KPI scales as performance indicators highlight the correlation between CRM activities of a DMO using social media channels to promote Ireland as a brand to North America and overall ROI. Kumar and Mirchandani [13] illustrate how return on investment is interpretative. In this study the empirical evidence provided by the Irish SMEs emphasises that ROI can be correlated by using TripAdvisor in conjunction with a balanced scorecard. Paine [26] posits that it is not how you measure social media activity but rather what you measure. While the DMO begin with content production and engagement, the SME analyses engagement relative to post consumption. Each of the approaches is relevant to this study's suggestive framework when using social media channels to maximise budget.

\section{REFERENCES}

[1] Pike, S. \& Page, S.J., Destination marketing organizations and destination marketing: A narrative analysis of the literature. Tourism Management, 41, pp. 202-227, 2014.

[2] TI, Tourism Ireland Marketing Report 2018. Available at www.tourismireland.com. Accessed on: 21 Dec. 2017.

[3] Barcoe, C. \& Barcoe, D., The habitual nature of the U.S. holidaymaker with regards to Ireland and social media usage. Tourism and Hospitality Research in Ireland: Entrepreneurs Driving Tourism and Hospitality, ed. J. Hanrahan, IT Sligo: Sligo, Ireland, pp. 199-212, 2017.

[4] Hoffman, D. \& Fodor, M., Can You Measure the ROI of Your Social Media Marketing? MIT Sloan Management Review, 52(1), 2010.

[5] Barcoe, C. \& Whelan, G., Capitalising on the Cultural Link between Ireland and North America Using Social Media: A Destination Marketing Study. www.IFTT.org. Accessed on: 19 Jan. 2018. 
[6] So, K.K.F., King, C. \& Sparks, B., Customer engagement with tourism brands: Scale development and validation. Journal of Hospitality \& Tourism Research, 38(3), pp. 304-329, 2014.

[7] Harrigan, P., Evers, U. \& Miles, M., Customer engagement with tourism social media brands. Tourism Management, 59, pp. 597-609, 2017.

[8] Sigala, M., How "bad" are you? Justification and normalisation of online deviant customer behaviour. Proceedings of the International Conference, Rome, Italy, 24-26 Jan. 2017.

[9] Chaffey, D., Smart insights. www.smartinsights.com. Accessed on: 21 Dec. 2017.

[10] Kaske, F., Kügler, M. \& Smolnik, S., Return on investment in social media - does the hype pay off? Towards an assessment of the profitability of social media in organizations. 45th Hawaii International Conference on System Sciences, pp. 38983907, 2012.

[11] Wright, A.D., Managing the American tourist experience in Ireland: An emotional context. International Journal of Business Management, 3(8), pp. 85-92, 2008.

[12] Felix, R., Rauschnabel, P.A. \& Hinsch, C., Elements of strategic social media marketing: A holistic framework. Journal of Business Research, 70, pp. 118-126, 2017.

[13] Kumar, V. \& Mirchandani, R., Increasing the ROI of Social Media Marketing. MIT Sloan Management Review, 2012.

[14] Merilinaen, K., From floating to leading: The transformation of digital marketing capabilities through ICT uptake in tourism SMEs. Information and Communication Technologies in Tourism, eds R. Schegg \& B. Stangl, Springer: Cham, pp. 89-100, 2017.

[15] Blanchard, O., Social Media ROI: Managing and Measuring Social Media Efforts in Your Organization. Pearson, 2011.

[16] Owyang, J., Tracking the influence of conversations: A roundtable discussion of social media metrics and measurement. Journal of Database Marketing \& Customer Strategy Management, 16(3), pp. 189-195, 2009.

[17] Chaffey, D., E-business and E-commerce Management: Strategy, Implementation and Practice. Harlow: Pearson, 2011.

[18] Pradiptarini, C., Social media marketing: Measuring its effectiveness and identifying the target market. UW-L Journal of Undergraduate Research, XIV, 2011.

[19] Mae-Kim, C., Social Media Compaigns, 1st ed. Routledge: New York, 2016.

[20] Fisher, T., ROI in social media: A look at the arguments. Journal of Database Marketing and Consumer Strategy, 16, pp. 189-195, 2009.

[21] Xiang Z. \& Gretzel, U., Role of social media in online travel information search. Tourism Management, 31(2), pp. 179-188, 2010.

[22] Shaw, S., Airline Marketing and Management, Seventh Edition. SAA: Oxfordshire, 2106.

[23] Fauver, J., Trekksoft. www.Trekksoft.com. Accessed on: 25 Jan. 2017.

[24] Evans, D., Social Media Marketing: An Hour a Day. Wiley: Chichester, 2010.

[25] Zuninga, J.G. \& Jung, N., Social media use for news and individuals' social capital, civic engagement and political participation. Journal of Computer-Mediated Communication, 17, pp. 319-336, 2012.

[26] Paine, K.D., Measure what matters: Online Tools for Understanding Customers, Social Media, Engagement, and Key Relationships. Wiley: Chichester, 2011. 